\begin{tabular}{|c|c|c|c|c|}
\hline $\begin{array}{c}\text { 118SHARE: SOCIAL WORK } \\
\text { JURNAL }\end{array}$ & VOLUME: 7 & NOMOR: 1 & HALAMAN: $1-129$ & $\begin{array}{l}\text { ISSN:2339 -0042 }(p) \\
\text { ISSN: 2528-1577 }(e)\end{array}$ \\
\hline
\end{tabular}

\title{
PENERAPAN METODE ORIENTASI MASA DEPAN (OMD) PADA REMAJA YANG MENGALAMI KEBINGUNGAN IDENTITAS (MENENTUKAN TUJUAN HIDUP)
}

\author{
APPLICATION OF FUTURE ORIENTATION METHOD IN \\ ADOLESCENTS WHO EXPERIENCED IDENTITY CONFUSION \\ (DETERMINE THE PURPOSE OF LIFE)
}

\author{
Oleh: \\ Salsabila Wahyu Hadianti ${ }^{1}$, Hetty Krisnani ${ }^{2}$ \\ 1. Mahasiswa Program Studi Sarjana (S-1) Ilmu Kesejahteraan Sosial FISIP-Universitas Padjadjaran) \\ 2. Pusat Studi Kesejahteraan Anak dan Keluarga FISIP-Universitas Padjadjaran \\ Email: \\ (swhyhadianti02@gmail.com¹, hettykrisnani@yahoo.com²)
}

\begin{abstract}
ABSTRAK
Secara biologis maupun kultural masa remaja dipandang sebagai akhir masa anak - anak dan merupakan pintu masuk menuju masa dewasa. Dalam tahap ini, seorang remaja tentunya diharapkan sudah dapat merumusukan minat mereka dalam hal - hal tertentu misalnya seperti pilihan karier (melanjutkan pendidikan atau mengikuti pelatihan pengembangan keterampilan), pilihan untuk menikah ataupun mengurus keluarga. Sebagaimana yang dikemukakan oleh Erikson Isu psikososial yang dialami pada tahap ini yakni terkait identitas versus kebingungan peran. Walaupun seyogyanya pada tahap ini remaja diharapkan telah memiliki gambaran terkait dirinya, namun Erikson juga menjelaskan bahwa dalam tahap ini masih terdapat sebagian remaja yang menghadapi kesulitan besar dalam mendefinisikan atau mengambil peran ataupun keyakinan tertentu dalam hidupnya yang tentunya hal ini memberikan dampak pada tugas perkembangan selanjutnya. Untuk mengatasi permasalahan tersebut, metode Orientasi masa depan (OMD) dirasa cocok untuk membantu remaja dalam menentukan tujuan masa depannya. Hal ini dikarenakan, OMD merupakan upaya antisipasi terhadap masa depan. Dalam hal ini, individu mulai memikirkan kebutuhan tentang masa depan secara sungguh-sungguh, memberikan perhatian kepada yang besar terhadap berbagai lapangan kehidupan yang akan dijalaninya dimasa yang akan datang.
\end{abstract}

Keywoard : Remaja, Tujuan, Orientasi Masa Depan.

\begin{abstract}
ABSTRAC
Adolescence is viewed as the end of their children phase and this is the entrance to adulthood phase. In this stage, a teenager is surely expected to already think about their interest in - such as career choice (continuing education or training skills development), the choice to get married or take care of the family. As expressed by Erikson psychosocial issues experienced at this stage i.e. related identity versus role confusion. Although in this stage the teenagers are expected to already have an idea related to himself, but Erikson explains that in this stage there is still some teenagers who have difficulties in defining or take the role or particular beliefs in his life that surely this gives a impact on the task of further development. To overcome these problems, future orientation method (OMD)
\end{abstract}


where appropriate to help teens in determining his/her future goals. This is because, OMD is an attempt against the anticipation of the future. In this case, the individual begins to think of the needs of the future in earnest, giving attention to the contribution of various field of life that would be suffered in the future.

Keywoard : Adolescene, Goals, Future Orientation.

\section{PENDAHULUAN (INTRODUCTION)}

Mengutip pendapat Monks, Remaja adalah individu yang memiliki rentang usia antara $12-21$ tahun. Sedangkan menurut pendapat Marheni dikemukakan bahwa masa remaja merupakan masa peralihan antara masa anak-anak dan masa dewasa, dimulai pada saat terjadinya kematangan seksual antara usia 11 atau 12 tahun sampai dengan 20 tahun, menjelang masa dewasa muda.

Secara biologis maupun kultural masa remaja dipandang sebagai akhir masa anak anak dan merupakan pintu masuk menuju masa dewasa. Dalam masa ini perubahan individu tentunya ditandai oleh beragam aktivitas sekaligus perubahan besar. Selain itu, tahapan ini juga dianggap sebagai tahapan dimana individu dapat mengembangkan identitas terkait dirinya. Dalam tahap ini, seorang remaja tentunya diharapkan sudah dapat merumusukan minat mereka dalam hal hal tertentu misalnya seperti pilihan karier (melanjutkan pendidikan atau mengikuti pelatihan pengembangan keterampilan), pilihan untuk menikah ataupun mengurus keluarga.

Pemahaman diatas semakin dipertegas oleh adanya pendapat yang dikemukakan oleh Jones dan Hartmann (1988) yang menjelaskan bahwa pada tahap ini dapat dikatakan pencarian identitas seorang remaja menjadi lebih kuat sehingga ia berusaha untuk mencari identitas dan mendefinisikan kembali siapakah ia saat ini dan akan menjadi siapakah ia di masa depan

Dalam tahap perkembangan psikososial sebagaimana yang dikemukakan oleh Erikson dijelaskan bahwa masa remaja digolongkan pada tahap perkembangan ke 5, isu psikososial yang dialami dalam tahap ini yakni terkait identitas versus kebingungan peran. Walaupun seyogyanya pada tahap ini, remaja diharapkan telah memiliki gambaran terkait dirinya, namun Erikson juga menjelaskan bahwa dalam tahap ini sebagian remaja menghadapi kesulitan besar dalam mendefinisikan atau mengambil peran ataupun keyakinan tertentu dalam hidupnya yang tentunya hal ini memberikan dampak pada tugas perkembangan selanjutnya.

Pendapat yang dikemukakan oleh Erikson diatas, sesuai dengan gambaran masalah yang ditangani oleh praktikan. Klien yang ditangani oleh praktikan selama kegiatan praktikum ini merupakan seorang remaja perempuan berusia 19 tahun dengan latar belakang keluarga broken home, yang mengalami kesulitan dalam merumuskan gambaran tentang dirinya terkait bagaimana minat serta tujuan hidup yang akan dicapainya dimasa yang akan datang serta tindakan tindakan apa sajakah yang harus ia lakukan kedepannya. Tidak adanya gambaran serta tujuan hidup terkait masa depan seperti apa yang harus diraih dimasa yang akan datang, hal ini didasari oleh adanya pemikiran serta nilai yang sejak lama tertanaman dalam diri klien bahwa hidup yang ia jalani hanya perlu atau cukup mengikuti alur yang ada.

Dengan tidak adanya rancangan atau planning terkait gambaran terkait masa depan yang diinginkan, hal ini tentunya berdampak pada kehidupan klien. Selain membuat klien menjadi kebingungan ketika harus menjawab pertanyaan terkait "kehidupan seperti apakah yang anda ingin dicapai selanjutnya?" atau "apa planning anda dimasa yang akan datang?", Hal yang utama adalah dengan tidak adanya gambaran terkait masa depan membuat klien : 1). tidak memiliki arah tindakan yang jelas atau tidak memiliki prioritas pilihan hidup; 2). tidak dapat memahami ataupun tidak mampu memanfaatkan kesempatan untuk mecapai keberhasilan hidup; 3). tidak dapat 
memahami kebutuhan atau prasyarat apa sajakah yang diperlukan dalam rangka mencapai tujuan; 4). tindakannya menjadi tidak terfokus dan; 5). membuat klien rentan mengalami stress.

Pentingnya dilaksanakan intervensi terkait persoalan diatas selain melihat banyaknya dampak yang ditimbulkan, hal ini juga mengingat bahwa terdapat tugas perkembangan yang harus dilalui oleh seorang remaja akhir yakni misalnya seperti mempersiapkan karir ekonomi, mempersiapakan perkawinan dan keluarga serta memperoleh perangkat nilai dan sistem etis sebagai pegangan untuk perilaku mengembangkan ideologi yang mana hal tersebut tentunya dapat dicapai apabila individu yang bersangkutan telah memiliki gambaran terkait dirinya seperti karir apakah yang ingin ia capai, kapan dan pernikahan seperti apa yang ingin ia bangun, serta kehidupan keluarga seperti apakah yang ingin ia bentuk dimasa yang akan datang. Selain itu, alasan kedua yang mendasari mengapa perlu dilakukan intervensi terkait masalah ini yakni bertujuan agar individu yang bersangkutan memiliki antisipasi terhadap kejadian kejadian yang mungkin timbul dimasa yang akan datang yang tentunya dapat meminimalisir stress yang timbul dalam diri klien.

\section{METODE (METHODS)}

\section{Metode Orientasi Masa Depan (OMD)}

Orientasi masa depan merupakan upaya antisipasi terhadap masa depan. Dalam hal ini, individu mulai memikirkan kebutuhan tentang masa depan secara sungguh-sungguh, memberikan perhatian kepada yang besar terhadap bebagai lapangan kehidupan yang akan dijalaninya dimasa yang akan datang.

Nurmi (dalam Steinberg, 2009) orientasi masa depan merupakan fenomena yang luas yang berhubungan dengan bagaimana seseorang berpikir dan bertingkah laku menuju masa depan yang dapat digambarkan dalam proses pembentukan orientasi masa depan, secara umum dibagi menjadi tiga tahap yaitu:

a) Tahapan Motivasi

Motivasi merupakan tahap awal pembentukan orientasi masa depan. Tahap ini mencakup motif, minat, dan tujuan yang berkaitan dengan orientasi masa depan. Pada mulanya remaja menetapkan tujuan berdasarkan perbandingan antara motif umum dan penilaian, serta pengetahuan yang telah mereka miliki tentang perkembangan sepanjang rentang hidup yang dapat mereka antisipasi. Ketika keadaan masa depan beserta faktor pendukungnya menjadi sesuatu yang diharapakan dapat terwujud, maka pengetahuan yang menunjang terwujudnya harapan tersebut menjadi dasar penting bagi perkembangan motivasi dalam orientasi masa depan.

b) Tahapan Perencanaan

Perencanaan merupakan tahap kedua proses pembentukan orientasi masa depan individu, yaitu bagaimana remaja membuat perencanaan tentang perwujudan minat dan tujuan mereka. Menurut Nurmi (1991), perencanaan dicirikan sebagai suatu proses yang terdiri dari tiga subtahap. Pertama, penentuan subtujuan. Pada subtujuan ini, individu membentuk suatu representasi dari tujuan-tujuannya dan konteks masa depan di mana tujuan tersebut di harapkan dapat terwujud. Kedua hal ini didasari oleh pengetahuan individu tentang konteks dari aktifitas di masa depan, dan sekaligus menjadi dasar menjadi dasar bagi kedua subtahap berikutnya.

- Penyususunan rencana.

Pada tahap ini individu membuat rencana dan menetapkan strategi untuk suatu rencana, individu dituntut menemukan caracara yang dapat mengarahkannya pada pencapaian tujuan dan menetukan cara mana yang paling efisien. Pengetahuan tentang konteks yang diharapkan dari suatu 


\begin{tabular}{|l|l|l|l|l|}
\hline $\begin{array}{c}\text { 118SHARE: SOCIAL WORK } \\
\text { JURNAL }\end{array}$ & VOLUME: 7 & NOMOR: 1 & HALAMAN: $1-129$ & $\begin{array}{l}\text { ISSN:2339 -0042 }(p) \\
\text { ISSN: } 2528-1577(e)\end{array}$ \\
\hline
\end{tabular}

aktifitas di masa depan menjadi dasar bagi perencanaan ini. Berbagai tindakan yang ditetapkan harus dievaluasi, sehingga tujuantujuan dan rencana-rencana yang telah disususn dapat diwujudkan.

- Melaksanakan rencana dan strategi yang telah disusun.

Dalam subtahap ini, individu dituntut melaksanakan pengawasan terhadap pelaksaan rencana tersebut. Pengawasan dapat dilakukan dengan membandingkan tujuan yang telah ditetapkan dengnan konteks yang sesungguhnya di masa depan. Artinya, selama melaksanakan rencana, individu harus melaksanakan pengawasan secara sistematis, apakah tujuan yang telah ditetapkan dapat didekati melalui system yang sedang dilaksanakan atau tidak. Jika tidak maka harus dilakukan perubahan terhadap rencana-rencana yang ada. Untuk menilai sebuah perencanaan yang dibuat oleh individu, dapat dilihat dari tiga variable yang tercakup di dalamnya, yaitu knowledge, plans, dan realization.

Dalam sebuah buku juga dijelaskan bahwa terdapat karakteristk sebuah tujuan atau goals yang dianggap baik yakni dijelaskan sebagai berikut :

"Effective goals - the kind that really do motivate - should be : concrete and spesific, realistic, measurable in some way, deadline - targeted, value achored, written (an unrecorded goals is only wish"

\section{c). Tahapan Evaluasi}

Tahap terakhir dari proses pembentukan orientasi masa depan. Menurut Nurmi (1991) memandang evaluasi sebagai suatu proses yang melibatkan pengamatan dan melakukan penilaian terhadap tingkah laku yang ditampilkan, serta memberikan penguat bagi diri sendiri. Dalam mewujudkan tujuan dan rencana dari orientasi masa depan ini, proses evaluasi melibatkan causal attributions yang disadari oleh evaluasi kognitif individu mengenai kesempatan yang dimiliki dalam mengendalikan masa depannya, dan affects yang berkaitan dengan kondisi-kondisi yang muncul sewaktu-waktu dan tanpa disadari. Dalam proses evaluasi ini, konsep diri memainkan peranan yang penting, terutama dalam mengevaluasi kesempatan yang ada untuk mewujudkan tujuan dan rencana sesuai dengan kemampuan yang dimiliki individu.

Proses atau Tahapan Pelayanan

Adapun proses atau tahapan dalam penanganan kasus dalam kegiatan praktikum ini dibagi menjadi beberapa bagian yakni dimulai dengan kegiatan assessment, plan of treatment (POT), treatment, evaluasi dan terimanasi.

a. Assessment, yakni tahap menggali maupun mengidentifikasi masalah dan kekuatan yang ada dalam diri klien.

b. Plan of Treatment (POT), yakni membuat rencana tindakan yang dibuat oleh pekerja sosial guna memecahkan masalah klien.

c. Treatment, yakni proses intervensi yang dilakukan guna memecahkan masalah klien.

d. Evaluasi, yakni suatu pemeriksaan terhadap pelaksanaan atau program yang telah dilakukan.

e. Terminasi, yakni pemutusan hubungan antara praktikan dan klien dalam rangka pemberian pertolongan.

\section{HASIL DAN PEMBAHASAN (RESULTS AND DISCUSSION)}

Dalam pelaksanaan praktiknya, praktikan melakukan kunjungan kerumah klien untuk melakukan proses pemberian layanan. Pada tahap awal, sebelum dilaksanakannya proses pelayanan praktikan dan klien membuat sebuah inform consent yakni sebuah lembar kesepakatan antara praktikan dan klien yang memuat pelaksanaan 


\begin{tabular}{|c|c|c|c|c|}
\hline $\begin{array}{c}\text { 118SHARE: SOCIAL WORK } \\
\text { JURNAL }\end{array}$ & VOLUME: 7 & NOMOR: 1 & HALAMAN: $1-129$ & $\begin{array}{l}\text { ISSN:2339 -0042 }(p) \\
\text { ISSN: } 2528-1577 \\
(e)\end{array}$ \\
\hline
\end{tabular}

terkait proses pemberian bantuan atau pelayanan.

Selanjutnya, praktikan melakukan kegiatan assessment terkait diri klien yang dilakukan secara berkala. Salah satu contoh dari kegiatan assessment dalam kegiatan ini adalah membimbing klien untuk mengisi sebuah form yang memuat kelebihan, kekurangan, masalah, dan aspek pribadi yang ingin dikembangkan oleh klien. Form ini

Tabel 1. Form Kelebihan, Kekurangan, Masalah, dan

Aspek Pribadi yang Ingin Dikembangkan

\begin{tabular}{|c|c|c|c|c|}
\hline NAMA & KELEBIHAN & KEKURANGAN & $\begin{array}{l}\text { MASALAH } \\
\text { JIKA ADA }\end{array}$ & $\begin{array}{l}\text { ASPEK PRIBADI } \\
\text { YANG INGIN } \\
\text { DIKEMBANGKAN }\end{array}$ \\
\hline \multirow{5}{*}{ Klien } & Mandiri & $\begin{array}{l}\text { Kurangme- } \\
\text { manage masa } \\
\text { depan }\end{array}$ & $\begin{array}{l}\text { Tidak } \\
\text { memiliki } \\
\text { planning } \\
\text { masa depan }\end{array}$ & $\begin{array}{l}\text { Ingin membuat } \\
\text { planning masadepan } \\
\text { seperti } \\
\text { pengembangan usaha }\end{array}$ \\
\hline & Periang & $\begin{array}{l}\text { Sering } \\
\text { memendam } \\
\text { perasaan }\end{array}$ & $\begin{array}{l}\text { Tidak berani } \\
\text { terbuka } \\
\text { dengan orang } \\
\text { sekitar }\end{array}$ & $\begin{array}{l}\text { Ingin bis a lebih } \\
\text { terbuka untuk } \\
\text { sharing atau berbagi } \\
\text { cerita }\end{array}$ \\
\hline & $\begin{array}{l}\text { Memiliki } \\
\text { simpati yang } \\
\text { tinggi terhadag } \\
\text { lingkungan } \\
\text { selkitar }\end{array}$ & Egois & $\begin{array}{l}\text { - Kurang } \\
\text { terbangun } \\
\text { hubungan } \\
\text { yangbaik } \\
\text { antar } \\
\text { saudara } \\
\text { - Suasana } \\
\text { rumah } \\
\text { yang } \\
\text { kurang } \\
\text { kondusif }\end{array}$ & $\begin{array}{l}\text { Mengelola kesabaran } \\
\text { dan meningkatkan } \\
\text { kemampuanuntuk } \\
\text { berkomunikasi }\end{array}$ \\
\hline & Pekerja keras & - & - & - \\
\hline & Mudah iba & - & - & - \\
\hline
\end{tabular}

dirasa menjadi penting dari bagian assessment, karena melalui pengisian setiap tabel yang tersedia di form ini klien dapat lebih menggali aspek yang ada dalam dirinya. Selain itu, form ini menjadi salah satu data bagi praktikan dan klien untuk menentukan hal apakah yang ingin diperbaiki atau dikembangkan melalui proses bimbingan dalam kegiatan ini. 
Dalam proses pendampingan juga digali beberapa aspek seputar kehidupan individu terkait 1). bagaimana hubungan klien dengan keluarganya maupun individu diluar keluarganya yakni melalui pembuatan ecomap dan genogram; 2). assessment keberfungsian sosial yang bertujuan untuk menggali keberfungsian sosial klien yang meliputi beberapa aspek diantaranya seperti dasar hidup mandiri, kewarganegaraan dan hal - hal yang berkaitan dengan hukum, penggunaan sumber daya di masyarakat, kehidupan keluarga, pertemanan dan dukungan sosial, spiritual dan aktifitas keagamaan, interaksi dengan komunitas, penampakan diri dan higienitas pendidikan dan pelatihan, pekerjaan dan performa kerja, manajemen keluarga dan kesadaran konsumen, rekresional dan kegiatan di waktu luang, tempat tinggal dan perawatan rumah, nutrisi dan perawatan kesehatan, mengatasi masalah kehidupan yang bisa terjadi, mengatasi masalah kesehatan mental atau adiksi; 3). form assessment ROPES dan; 4). form assessment - perspektif kekuatan.

Tabel 2. Salah Satu Isi Form Perspektif

Kekuatan

\begin{tabular}{|c|c|}
\hline & $\begin{array}{l}\text { Fokus masa depan (future } \\
\text { focus) } \\
\text { Fokus masa depan yang ingin } \\
\text { dicapai oleh klien yakni } \\
\text { diantaranya: } \\
\text { - Usaha yang dirintis klien } \\
\text { berjalan lancar } \\
\text { - Klien ingin adiknya dapat } \\
\text { menempuh pendidikan lebih } \\
\text { tinggi / perkuliahan } \\
\text { - Klien ingin menikah } \\
\text { diusia } 24 \text { tahun } \\
\text { Imagination } \\
\text { - Klien ingin usaha yang } \\
\text { dijalaninya saat ini dapat } \\
\text { berkembang pesat, misalnya } \\
\text { membuka cabang, memiliki } \\
\text { pekerja, pendapatannya } \\
\text { banyak sehingga bisa } \\
\text { digunakan untuk membeli } \\
\text { mobil dan rumah } \\
\text { • Dst... }\end{array}$ \\
\hline
\end{tabular}

Salah satu aspek yang digali dalam assessment perspektif kekuatan yakni terkait possibilities (kemungkinan) yang memuat tentang fokus masa depan, dan imaginasi terkait masa depan yang ia harapkan. Hal ini dirasa relevan dengan metode Orientasi Masa Depan (OMD) dikarenakan fokus masa depan yang diinginkan oleh klien selanjutnya ini dapat diturunkan menjadi rencana kegiatan yang akan dibuat dan dilaksanakan oleh klien.

Orientasi Masa Depan (OMD) dipilih dalam proses pemberian layanan hal ini didasari selain melihat hasil atau data assessment yang dilakukan sebelumnya, hal ini juga atas dasar keinginan, pendapat dan juga kesepakatan dari klien.

Dalam membuat Orientasi Masa Depan (OMD) dilakukan melalui tahapan sebagai berikut:

a. Tahap Motivasi

Adapun motivasi atau tujuan yang ingin dicapai oleh klien terkait masa depannya yakni terkait pengembangan usaha, pendidikan bagi adiknya, dan pernikahan.

b. Tahap Perencanaan

Dalam tahap ini, tujuan yang telah ditetapkan oleh klien diatas diturunkan menjadi beberapa kegiatan. Namun mengingat keterbatasan waktu dalam proses pemberian layanan ini, sehingga praktikan dan klien membuat keputusan bahwa pembuatan perencanaan dan pelaksanaan perancanaan ditunjukan bagi poin pertama yakni terkait pengembangan usaha yang dilaksanakan kurang lebih 2 minggu.

Gambar 1. Sebuah goals yang baik adalah goals yang dituliskan 


\begin{tabular}{|c|c|c|c|c|}
\hline $\begin{array}{c}\text { 118SHARE: SOCIAL WORK } \\
\text { JURNAL }\end{array}$ & VOLUME: 7 & NOMOR: 1 & HALAMAN: $1-129$ & $\begin{array}{l}\text { ISSN:2339 -0042 }(p) \\
\text { ISSN: 2528-1577 }(e)\end{array}$ \\
\hline
\end{tabular}

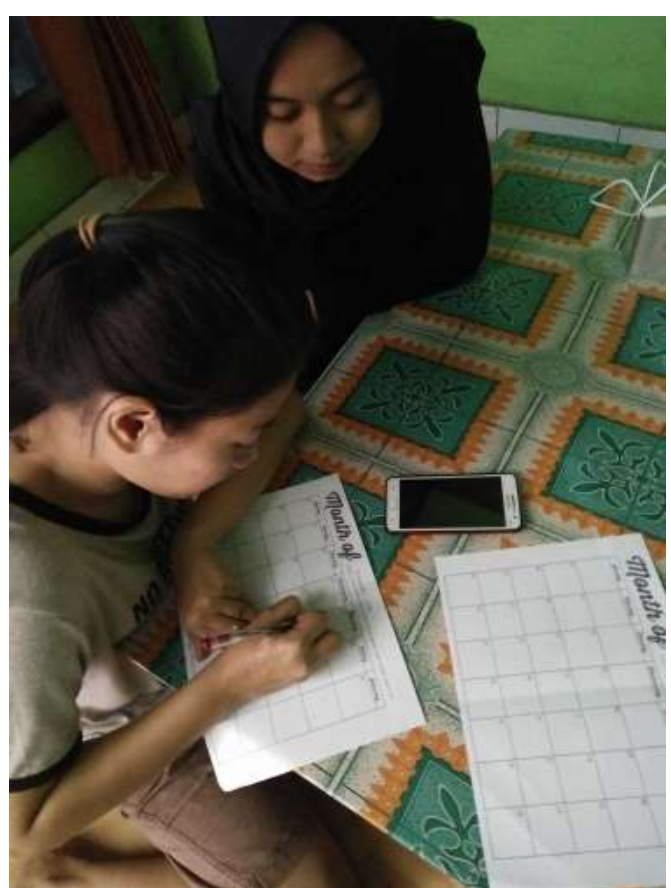

Sumber: Dokumen Pribadi

Tabel 3. Rincian Kegiatan

\begin{tabular}{|c|c|}
\hline $\begin{array}{c}\text { TUJUAN } \\
\text { ATAU GOALS } \\
\text { YANG AKAN } \\
\text { DICAPAI }\end{array}$ & $\begin{array}{l}\text { RINCIAN KEGIATAN YANG } \\
\text { AKAN DILAKUKAN } \\
\text { (RENCANA AKSI) }\end{array}$ \\
\hline \multirow{6}{*}{$\begin{array}{l}\text { Pengembangan } \\
\text { Usaha }\end{array}$} & 1. Membuat Kartu Nama \\
\hline & $\begin{array}{ll}\text { 2. } & \begin{array}{l}\text { Melakukan promosi } \\
\text { melalui media sosial }\end{array}\end{array}$ \\
\hline & 3. $\begin{array}{l}\text { Survei lokasi untuk } \\
\text { pembukaan cabang baru }\end{array}$ \\
\hline & $\begin{array}{l}\text { 4. Membuat peralatan } \\
\text { keperluan usaha (untuk } \\
\text { cabang baru) }\end{array}$ \\
\hline & $\begin{array}{l}\text { 5. Menentukan inovasi } \\
\text { terkait menu ditempat } \\
\text { usaha. }\end{array}$ \\
\hline & $\begin{array}{l}\text { 6. Membuat buku catatan } \\
\text { pengeluaran harian }\end{array}$ \\
\hline
\end{tabular}

c. Tahap Evaluasi

Dalam tahap ini, klien melakukan evaluasi terhadap proses kegiatan yang telah dibuat dan dilakukan. Dalam menjalankan kegiatan perencanaan dalam proses OMD ini klien sempat mengalami hambatan yakni hambatan yang berasal dari lingkungan eksternal misalnya ketika sulitnya mencari lokasi yang strategis untuk membuka cabang. Namun, secara keseluruhan dapat dikatakan bahwa pelaksanaan kegiatan ini berjalan dengan lancar, hal ini didasari karena adanya faktor motivasi yang kuat dalam diri klien.

\section{SIMPULAN DAN SARAN (CONCLUSION AND SUGGESTION) Simpulan}

Metode yang digunakan dalam kegiatan praktikum ini adalah metode Orientasi Masa Depan. Hal ini bertujuan aga klien mampu membuat planning terkait tujuan hidup dimasa yang akan datang, selain itu treatment ini dilakukan agar klien juga memiliki gambaran terkait dirinya. Segala bentuk kegiatan atau metode yang digunakan dalam kegiatan dalam kegiatan praktikum ini didasarkan pada kesepakatan yang telah disetujui oleh klien dan juga praktikan.

Dalam pelaksanaan kegiatannya, penanganan kasus dalam kegiatan praktikum ini terbagimenjadi beberapa bagian yakni diantaranya :

a. Assessment,

Hasil yang didapatkan dari kegiatan ini meliputi kelebihan, kekurangan, masalah dan aspek yang ingin dikembangkan oleh klien; bagaimana hubungan yang terjalin antara klien dengan lingkungan sosialnya seperti keluarga dekat, keluarga besar, dan teman - temannya melalui pembuatan genogram dan ecomap; latar belakang perceraian orang tua klien; pembahasan terkait usaha yang sedang dirintis oleh klien; keberfungsian sosial klien; penggalian informasi lebih dalam melalui assessment ROPES dan perspektif kekuatan.

Assessment yang dilakukan secara mendalam ini, digunakan sebagai sumber infomasi bagi praktikan dalam membantu klien. Tahap ini menjadi tahap dasar yang sangat penting, bagi pembuatan intervensi.

b. Plan Of Treatment (POT),

Hasil yang didapat dari tahap ini, klien membuat atau mencatat planning 


\begin{tabular}{|c|c|c|c|c|}
\hline $\begin{array}{c}\text { 118SHARE: SOCIAL WORK } \\
\text { JURNAL }\end{array}$ & VOLUME: 7 & NOMOR: 1 & HALAMAN: $1-129$ & $\begin{array}{l}\text { ISSN:2339 -0042 (p) } \\
\text { ISSN: 2528-1577 }(e)\end{array}$ \\
\hline
\end{tabular}

tidakan yang lebih terfokus yang ditunjukan untuk jangka waktu satu bulan.

c. Treatment,

Treatment yang dilakukan dalam kegiatan praktikum ini berhasil, hal ini karena praktikan melihat dan meninjau secara langsung setiap tahap yang dilakukan oleh klien.

d. Evaluasi dan

Hasil evaluasi dari kegiatan praktikum ini guna menggali manfaat yang dirasakan oleh klien dan hal apa sajakah yang perlu diperbaiki oleh praktikan.

e. Terminasi.

Hasil dari terminasi yang dilakukan oleh praktikan bersama klien, menunjukan bahwa kegiatan pendampingan ini dinyatakan telah selesai.

Kegiatan praktikum yang telah dilaksanakan selama kurang lebih 4 bulan telah terlaksana dengan baik. Adapun capaian dalam pelaksanaan proses bimbingan dalam kegiatan praktikum ini diantaranya yakni klien memiliki arah tindakan yang jelas, klien menjadi memahami bagaimana memanfaatkan kesempatan untuk mencapai tujuan yang ingin dicapai dimasa yang akan datang, kemampuan klien menjadi lebih bertambah dalam menganalisa prasyarat yang dibutuhkan dalam rangka mencapai tujuan, tindakannya menjadi terfokus, memiliki wawasan baru dan klien dapat lebih terbuka.

\section{Saran}

Adapun saran yang dapat digunakan untuk mencapai hasil yang maksimal yakni sebagai berikut :

a. Pembuatan planning untuk kegiatan klien sebaiknya tidak hanya dicatat atau dibuat dalam jangka waktu dekat saja, namun juga pada jangka waktu menengah dan jangka waktu panjang. Hal ini bertujuan agar klien memiliki tujuan dan tidakan yang harus dilakukan setiap harinya. Selain itu, klien juga perlu mencatat hal - hal apa sajakah yang diperlukan sehingga ia memiliki antisipasi apabila kegiatan yang ia lakukan tidak sesuai dengan rencana yang telah ditetapkan.

b. Agar klien dapat mencapai apa yang telah ditetapkannya, hal ini memerlukan dukungan dari lingkungan sosial sekitarnya seperti keluarga, peer group, atau pasangannya.

\section{UCAPAN TERIMAKASIH}

Tidak lupa penulis juga mengucapkan terimakasih kepada pihak - pihak yang membantu kelancaran penyusunan artikel ini :

1. Orang Tua Penulis yang senantiasa memberikan semangat dan doanya;

2. Ibu Dra. Hj. Hetty Krisnani., M.Si selaku dosen pembimbing yang senantiasa memberikan masukan dan semangat penulis agar dapat menyelesaikan tugas ini dengan baik;

3. Bapak dan Ibu Dosen Mata Kuliah Pratikum Mikro;

4. Klien beserta keluarga yang telah bersedia membagi kisah hidupnya dan menjadi bagian dari kegiatan konseling;

5. Teman-teman yang selalu setia membantu dalam hal mengumpulkan data-data dalam pembuatan artikel ini;

\section{DAFTAR PUSTAKA}

Chaplin, J.P. 2008. Kamus Lengkap Psikologi. Jakarta : Raja Grafindo Persada.

Hurlock, E.B. 1990. Psikologi Perkembangan. Jakarta : Erlangga.

Marheni. 2004. Perkembangan Psikososial dan Kepribadian Remaja. Jakarta : Sagung Solo.

Monks, F.J., Knoers \& Haditono. 1999. Psikologi Perkembangan Pengantar Dalam Berbagai Bagiannya. Yogyakarta : Gajah Mada University Press. 


\begin{tabular}{|c|c|c|c|c|}
\hline $\begin{array}{c}\text { 118SHARE: SOCIAL WORK } \\
\text { JURNAL }\end{array}$ & VOLUME: 7 & NOMOR: 1 & HALAMAN: $1-129$ & $\begin{array}{l}\text { ISSN:2339 -0042 }(p) \\
\text { ISSN: } 2528-1577(e)\end{array}$ \\
\hline
\end{tabular}

Raharjo, ST. 2015. "Pekerjaan Sosial Generalis, Suatu Pengantar Bekerja Bersama Organisasi dan Komunitas", Edisi Revisi Buku, Unpad Press,

Raharjo, ST. 2015. "Dasar Pengetahuan Pekerjaan Sosial”, Buku, Unpad Press

Raharjo, ST., Taftazani, BM., Apsari, NC., Santoso, MB. 2016. "PANDUAN PRAKTIKUM MIKRO (Konseling dan Pengembangan Diri)". Buku . Unpad Press.
Raharjo, ST. 2015. "Assessment dan Wawancara dalam Prakti Pekerjaan Sosial dan Kesejahteraan Sosial", Edisi Revisi Buku, Unpad Press

Salkin, Neil J. 2009. Teori - Teori Perkembangan Manusia. Bandung : Nusa Media.

Steinberg. 2009. Adolescene. Sanfransisco : McGraw - Hill. 